East Tennessee State University

Digital Commons @ East Tennessee State University

$5-7-2021$

\title{
Cleft Lip and/or Palate in Infants Prenatally Exposed to Opioids
}

\author{
Kerry Proctor-Williams \\ East Tennessee State University, williamk@etsu.edu \\ Brenda Louw \\ East Tennessee State University, louwb1@etsu.edu
}

Follow this and additional works at: https://dc.etsu.edu/etsu-works

Part of the Communication Sciences and Disorders Commons

\section{Citation Information}

Proctor-Williams, Kerry; and Louw, Brenda. 2021. Cleft Lip and/or Palate in Infants Prenatally Exposed to Opioids. The Cleft Palate-Craniofacial Journal. https://doi.org/10.1177/10556656211013687 PMID: 33960243 ISSN: 1055-6656

This Article is brought to you for free and open access by the Faculty Works at Digital Commons @ East Tennessee State University. It has been accepted for inclusion in ETSU Faculty Works by an authorized administrator of Digital Commons@ East Tennessee State University. For more information, please contact digilib@etsu.edu. 
Cleft Lip and/or Palate in Infants Prenatally Exposed to Opioids

This article is available at Digital Commons @ East Tennessee State University: https://dc.etsu.edu/etsu-works/8990 


\title{
Cleft Lip and/or Palate in Infants Prenatally Exposed to Opioids
}

The Cleft Palate-Craniofacial Journal I-9

(C) 2021, American Cleft PalateCraniofacial Association Article reuse guidelines: sagepub.com/journals-permissions DOI: I0.II77/I05566562 II0I3687 journals.sagepub.com/home/cpc (S)AGE

\author{
Kerry Proctor-Williams, PhD, CCC-SLP' ${ }^{\top}$ \\ and Brenda Louw, DPhil, SLP'
}

\begin{abstract}
Objective: To determine the prevalence and odds ratios for cleft lip and/or palate (CL/P) among infants prenatally exposed to opioids with or without neonatal opioid withdrawal syndrome (NOWS).

Design: This study represents an exploratory, retrospective cohort study design of newborn medical health records from $201 \mathrm{I}$ to 2016.

Setting: Records were drawn from a regional health system located in South Central Appalachia.

Population and Study Sample: The original population yielded 3 cohorts of infants: (I) infants with opioid exposure (OE) but not requiring pharmacological intervention (OE; $N=168) ;(2)$ infants with NOWS requiring pharmacological intervention $(N=294)$; and (3) infants with no opioid exposure ( $\mathrm{NOE} ; \mathrm{N}=16090$ ), the primary comparison group.

Main Outcome: Infants in the NOWS and OE groups showed significantly increased prevalence and odds ratios for CL/P when compared to those in the NOE group.

Results: Prevalence rates per 1000 live births for infants with OE (35.7I) and infants with NOWS (6.80) were significantly higher than those for infants with NOE (I.37). Comparison of infants with OE to the NOE group revealed significantly increased odds for $\mathrm{CL} / \mathrm{P}$, isolated cleft palate (CP), cleft lip (CL), and cleft lip and palate (CLP) $(27.05,4 \mathrm{I} .8 \mathrm{I}, 19.26,19.37$, respectively; all Ps <.008). The odds ratios for infants with NOWS compared to the NOE group were significantly higher for CL/P and CP (5.00 and I0.98, respectively; $\left.P_{s}<.03\right)$ but not for $C L$ and $C L P$.

Conclusion: The results provide additional evidence that prenatal $O E$ should be considered among the critical environmental risk factors that can contribute to CL/P.
\end{abstract}

\section{Keywords}

epidemiology, hard palate, fetal development, palatal development, prenatal development, soft palate, etiology, drug use

\section{Introduction}

The United States is experiencing an opioid crisis which has important implications for cleft care. Among those caught in this epidemic are pregnant women, putting their unborn and newborn babies at immediate health risk and at later long-term risk for adverse neurodevelopmental and academic outcomes (Oei et al., 2017; Fill et al., 2018; Benninger et al., 2020). As a result, the serious public health problem of prescription drug use, misuse, and abuse in the United States is emerging as a possible new environmental risk factor for cleft lip and/or palate $(\mathrm{CL} / \mathrm{P})$.

Based on the 2015 National Survey on Drug Use and Health (NUSDUH), approximately 91.8 million Americans adults used opioids, 11.5 million illicitly used or misused opioid pain relievers, 0.8 million used heroin, and 1.9 had an opioid use disorder (Wu et al., 2016; Han et al., 2017). Furthermore, there may be an additional 2.5 million or more individuals not included in the NUSDUH survey who receive legitimate opioid prescriptions but have an opioid use disorder nonetheless (Kolodny et al., 2015).

\footnotetext{
' Department Audiology and Speech-Language Pathology, East Tennessee State University, Johnson City, TN, USA
}

\section{Corresponding Author:}

Kerry Proctor-Williams, PhD, CCC-SLP, Department of Audiology and Speech-Language Pathology, East Tennessee State University, P.O. Box 70643, Johnson City, TN 376I4, USA.

Email:williamk@etsu.edu 
Over the last decade, prescribed use of opioids such as morphine, hydrocodone, and oxycodone for pain during pregnancy has increased substantially (Bateman et al., 2014; McQueen and Murphy-Oikenen, 2016). Several large-scale studies have found that more than $20 \%$ of women fill a prescription for a schedule $\mathrm{C}$ pain reliever during pregnancy, even following the addition of warning labels on boxes (Yang et al., 2008; Desai et al., 2014; Raval et al., 2014). Women's illicit use of opioids further adds to the risk of prenatal exposure to the fetus.

Prenatal exposure to opioids and other drugs can have immediate and serious consequences for newborns. For about half of all prenatally drug exposed newborns, this includes a condition now called neonatal opioid withdrawal syndrome (NOWS) by federal agencies such as the US Food and Drug Administration (Jones et al., 2010; Patrick et al., 2020). It was previously called Neonatal Abstinence Syndrome, or NAS, which included withdrawal from drugs other than opioids as well (Patrick et al., 2020). Neonatal opioid withdrawal syndrome includes a constellation of physiological and behavioral characteristics that occur in a newborn infant because of the sudden systemic withdrawal at birth from the drugs, usually opioids, which the mother used during pregnancy (Finnegan et al., 1975; Kocherlakota, 2014; Barfield, 2016). It is important to note that not all prenatally drug exposed infants experience NOWS, but many do experience some withdrawal symptoms and are at-risk, nonetheless.

Accordingly, it does not come as much of a surprise that along with the increasing rates of opioid use during pregnancy, rates of NOWS have also dramatically increased (Davies et al., 2016). Between 2000 and 2009, the incidence of NOWS in the United States increased more than $300 \%$. By 2012, the incidence of NOWS was 5.8 cases per 1000 births and prevalence was $30 \%$ to $50 \%$ of prenatally opioid exposed infants. Thus, about every 15 minutes in the United States a baby is born who experiences opioid withdrawal and every hour a baby is diagnosed with NOWS (Centers for Disease Control and Prevention, 2013; Patrick et al., 2015; Ko et al., 2016; National Institute on Drug Abuse, 2016; 2019).

\section{Opioids as Teratogens for CL/P}

According to Lind et al. (2017), the potential teratogenic effects of opioids during pregnancy are an area of great public health concern given that congenital disorders are serious, often costly, and can cause lifelong challenges. Broussard et al. (2011) and Yazdy et al. (2015) linked opioid use during pregnancy to congenital malformations.

The role of opioids as an environmental teratogen specifically in the development of $\mathrm{CL} / \mathrm{P}$ has been studied for a number of years. Saxén (1975a) explored the link between maternal influenza, drug consumption and oral clefts in 599 children with oral clefts and matched controls. The conclusion was reached that the drugs, rather than the influenza, were teratogenic agents. In a second study (Saxén, 1975b), associations between drug consumption during pregnancy and children with oral clefts revealed an association between drug use and the birth of children with cleft lip with or without cleft palate. Bracken and Holford (1981) investigated the exposure to prescribed drugs in pregnancy and the association with congenital malformations in a case-control study involving 1427 identified infants and 3001 control cases, respectively. The authors posited that an association existed between prenatal fetal opioid exposure (OE) and CL/P. Bracken and Holford (1981) called for further research on the impact of simultaneous exposure to environmental factors and interactions of the many different substances to which the maternofetal unit could be exposed.

In another cohort study by Thomas (1995) on substance abusing mothers and CL/P in Australia over a 10-year period, it was determined that there was a ten-fold increase in CL/P in comparison to general incidence figures and a very high occurrence of Sudden Infant Death Syndrome. Thomas (1995) pointed out that although there was no evidence that narcotic drugs alone were teratogenic, other environmental factors such as low socio-economic status, low levels of maternal education, suboptimal nutritional status of the mothers, and polysubstance use could lead to an increased risk of structural anomalies. A retrospective cohort study was conducted by Meyer et al. (2015) on 609 opioid dependent pregnant women treated with methadone $(\mathrm{n}=248)$ versus buprenorphine $(\mathrm{n}=361)$ during pregnancy. Two infants had congenital malformations: 1 infant was born with an absent hand to a mother who conceived while being treated with methadone, and 1 infant was born with an isolated cleft palate to a mother who conceived while being treated with buprenorphine.

Recently Lind et al. (2017) conducted a systematic review to evaluate the association between prenatal opioid use and congenital malformations. Of the 68 studies included in the review, 17 studies (10 of 12 case control, and 7 of 18 cohort studies) documented statistically significant positive associations between prenatal opioid use and congenital malformations. Among the 10 case-control studies, clefts and ventricular/atrial septal defects were the most frequently reported specific malformations. However, Lind et al. (2017) concluded that uncertainty remains regarding the teratogenicity of opioids. Results were therefore inconclusive regarding the impact specifically of $\mathrm{OE}$ during pregnancy and the impact on the development of $\mathrm{CL} / \mathrm{P}$.

Most recently 2 very large retrospective cohort studies were conducted by Mullens et al. (2019) and Danis et al. (2020) to better understand the association between NOWS and CL/P. Mullens et al. (2019) analyzed 11599 live hospital births in West Virginia University's tertiary care center between 2013 and 2017. Findings indicated a higher prevalence of CL/P in infants with NOWS (6.79 per 1000 live births) as compared to 1.63 per 1000 live births in the general population. Isolated cleft palate (CP) and isolated cleft lip (CL) were significantly more prevalent in NOWS patients compared to the general population and were associated with in-utero OE (Mullens et al., 2019). Danis et al. (2020) used the 2016 nationwide Kid's Inpatient Database to evaluate the associations between NOWS and $\mathrm{CL} / \mathrm{P}$ in the United States. The data set consisted of 3769 272 weighted in-hospital births. Danis et al. also determined an 
association between NOWS and CL/P, specifically for isolated $\mathrm{CP}$, suggesting that prenatal exposure to opioids may be an environmental risk factor in the development of $\mathrm{CL} / \mathrm{P}$. Both these studies call for further research to better characterize this relationship, which is not yet well understood despite the growing body of research.

\section{Rationale and Hypotheses}

Motivating the current study, an early research project on Speech-Language Pathology services for infants with NOWS in a Neonatal Intensive Care Unit of the local health system revealed a surprising number of infants with NOWS and CL/P (Bowman et al., 2018). At about the same time, clinical faculty anecdotally reported an increase in infants with prenatal OE or NOWS and submucous clefts at the ETSU Speech-Language Hearing Clinic. Then, the eye-opening publication of Mullens et al. (2019) appeared. Shortly after its publication, we gained access to a large local database that included infants with NOWS, prompting consideration of a population-based replication study. While engaged in data analysis in our study, Danis et al. (2020) published their research and we realized we could extend the findings of the Mullens et al. (2019) and Danis et al. (2020) studies by more specifically describing the sample in 3 ways. First, we defined a novel experimental group: infants prenatally opioid exposed but without NOWS. Second, we confirmed that infants coded as NOWS actually met diagnostic criteria for NOWS. Finally, we focused on infants whose primary prenatal drug exposure was to opioids.

We hypothesized that across $\mathrm{CL} / \mathrm{P}$ categories, infants with NOWS would have prevalence rates and odds ratios higher than those not exposed to opioids (Mullens et al., 2019; Danis et al., 2020). We had no predictions about infants prenatally opioid exposed but without NOWS.

\section{Methods}

\section{Research Ethics}

The East Tennessee State University Medical Institutional Review Board reviewed the study protocol, granted ethics approval, and ensured that Health Insurance Portability and Accountability Act regulations were followed. The researchers received only deidentified information.

\section{Research Design}

This study represents an exploratory, retrospective, cohort design to examine the prevalence, odds-ratios, demographic, and potentially contributing factors of $\mathrm{CL} / \mathrm{P}$ in infants with $\mathrm{OE}$ or with NOWS.

\section{Population}

The Ballad Health System chart review database, which houses electronic health records from the system's delivery hospitals provided the information used in this study. Ballad Health
System is an Appalachian regional health care organization that serves communities in Northeast Tennessee, Southwest Virginia, and Southeast Kentucky. For this retrospective study, the extracted database included all newborn records $(N=18$ 728) from 5-year period (July 1, 2011-June 30, 2016). Of these, 16597 charts were sufficiently complete for the purposes of the study. Of these, 16090 infants who were not exposed to drugs, including opioids, comprised the reference group for the study sample.

\section{Study Sample}

Infants with NOWS. From this initial database, the medical records of all infants $(\mathrm{n}=507)$ who received an International Classification of Disease, Ninth Revision (ICD-9) (779.5) or International Classification of Disease, Tenth Revision (ICD10) code (P96.1) for NOWS, received a detailed review to confirm prenatal OE and a criterion-based diagnosis of NOWS. Prenatal OE was determined by either a positive maternal urine drug screen and/or report at delivery. The NOWS criteria for pharmacological treatment used in the Ballad Health System was 2 consecutive Modified Finnegan (Jansson et al., 2009) scores of 10. Of the original 507 infants receiving a NOWS ICD code, 45 were excluded because their drug exposure did not include opioids or their exposure to opioids was postnatal, rather than prenatal. Thus, the detailed review resulted in identification of 462 infants who were opioid exposed. Of these infants, 294 were identified with NOWS and 168 were not. All infants opioid exposed received an additional code to indicate their status. This resulted in 2 mutually exclusive opioid exposed groups: infants without NOWS and infants with NOWS.

This study sample is unique in the vigilance taken to define the sample. First, it included only infants whose prenatal drug exposure involved opioids. Second, it included only infants prenatally opioid exposed. It did not include infants who experienced withdrawal in response to postnatal opioid exposure as a result of surgeries (eg, for heart defects, necrotizing enterocolitis, etc). Finally, infants were categorized based on objective criteria recorded in the medical record and not on $I C D$ codes alone.

Infants with CL/P. Because the time of record collection spanned the transition from use of $I C D-9$ to $I C D-10$, both sets of codes were used to identify the presence of CP, CL, or CLP (see Table 1). In total, the database included 30 infants with CL/ P: 22 who were not opioid exposed (NOE); 6 who were opioid exposed but not NOWS; and 2 who were opioid exposed with NOWS.

\section{Potential Confounding Variables}

To examine whether it was possible that opioids served as a potential teratogenic agent, other potentially confounding variables available in the database that have known links to CL/P were examined. These fell into 4 categories: demographic 
Table I. ICD-9 and ICD-IO Codes Used to Identify Presence of CP, CL, and CLP.

\begin{tabular}{lll}
\hline Diagnoses & \multicolumn{1}{c}{ ICD-9 } & \multicolumn{1}{c}{ ICD-10 } \\
\hline CP & $749.00,749.01,749.02,749.03,749.04$ & Q35.I, Q35.3, Q35.5, Q35.9 \\
CL & $749.10,749.11,749.12,749.13,749.14$ & Q36.0, Q36.I, Q36.9, \\
CLP & $749.20,749.21,749.22,749.23,749.24,749.25$ & Q37.0, Q37.I Q37.2, Q37.3, Q37.4, Q37.5, Q37.8, Q37.9 \\
\hline
\end{tabular}

Abbreviations: CL, cleft lip; CLP, cleft lip and palate; CP, cleft palate only; ICD, International Classification of Disease.

Table 2. Odds Ratios for All Types of CL/P for the OE and NOWS Groups Compared to NOE Group.

\begin{tabular}{|c|c|c|c|c|c|}
\hline Cleft type & $\mathrm{n}$ & Odds ratio & $95 \% \mathrm{Cl}$ & z & $P$ \\
\hline \multicolumn{6}{|c|}{ Infants with $\mathrm{OE}$} \\
\hline CL/P & 6 & 27.05 & $10.82-67.60$ & 7.057 & $<.0001^{\mathrm{a}}$ \\
\hline$C L$ & 3 & 41.81 & $10.72-163.10$ & 5.375 & $<.0001^{\mathrm{a}}$ \\
\hline $\mathrm{CP}$ & I & 19.26 & $2.24-165.78$ & 2.694 & $.0071^{\mathrm{a}}$ \\
\hline CLP & 2 & 19.37 & $4.21-89.10$ & 3.807 & $.0001^{\mathrm{a}}$ \\
\hline \multicolumn{6}{|c|}{ Infants with NOWS } \\
\hline $\mathrm{CL} / \mathrm{P}$ & 2 & 5.00 & $1.17-21.37$ & 2.173 & $.03^{\mathrm{a}}$ \\
\hline $\mathrm{CL}$ & 0 & 3.64 & $0.21-63.89$ & 0.884 & .38 \\
\hline $\mathrm{CP}$ & I & 10.98 & I.28-94.27 & 2.184 & $.029^{a}$ \\
\hline CLP & I & 5.49 & $0.70-43.01$ & 1.621 & .105 \\
\hline
\end{tabular}

Abbreviations: CL, cleft lip only; CLP, cleft lip and palate; CL/P, cleft lip and/or cleft palate; $\mathrm{Cl}$, confidence interval; $\mathrm{CP}$, cleft palate only; $n$, population size; NOWS, neonatal opioid withdrawal syndrome; OE, opioid exposed; $p$, statistical probability; $z$, standard deviation.

${ }^{a}$ Significant at $P<.05$.

variables, birth-related variables, maternal health variables, and other drug exposures. The variables related to these categories and available in the database can be seen in Table 2.

\section{Data Analysis}

Data analysis was conducted to test the hypotheses. Associations between NOWS and CL/P were quantified by calculating prevalence rates and odds ratios for the reference and study groups: (1) infants not prenatally opioid exposed (NOE); (2) infants opioid exposed, not NOWS (OE); and (3) infants with NOWS requiring pharmacological care (NOWS). Odds ratios were determined using the MEDCALC ${ }^{\odot}$ online statistical program, version 19.4, Odds Ratio Calculator (Altman, 1991; Sheskin, 2004, as cited in $\mathrm{MEDCALC}^{\odot}$ ). As no infants with NOWS had CL, 0.5 was added to all cells (Deeks and Higgins, 2010; Pagano and Gauvreau, 2000, as cited in MEDCALC $^{\odot}$ ).

Associations between the reference group (NOE) and the opioid exposed groups (OE and NOWS) with other potential confounding variables were compared using Fisher exact test, 1-tailed, for categorical data, and $t$-tests for independent samples with continuous data (Hays, 1994; Kim, 2017) using STATISTICA $^{\odot}$ data analysis software system (2009).

\section{Results}

Examination of the database revealed that $\mathrm{CL} / \mathrm{P}$ was present in all groups: NOE, OE, and NOWS.

\section{Population, Sample, and Prevalence}

The prevalence of CL/P was 1.37, 35.71, and 6.80 per 1000 live births in the NOE, OE, and NOWS groups, respectively as shown in Figure 1.

\section{Odds Ratios}

Comparison of infants with $\mathrm{OE}$ to the NOE reference group revealed significantly increased odds for $\mathrm{CL} / \mathrm{P}, \mathrm{CP}, \mathrm{CL}$, and CLP (see Table 2). For infants with OE, odds ratios ranged from 19.26 to 41.8 (all $P \mathrm{~s}<.008$ ). Furthermore, the odds of infants with $\mathrm{OE}$ were higher for each type of $\mathrm{CL} / \mathrm{P}$ than were those of infants with NOWS in comparison to the infants with NOE. The odds ratio for infants with NOWS in comparison with infants with NOE were significant for CL/P and CP (both $P \mathrm{~s}<.03$ ) but not for or CL and CLP (both $P \mathrm{~s}>.11$ ).

\section{Infant Demographic and Birth Variables}

The infants with $\mathrm{OE}$ and those with NOWS did not differ significantly from the infants in the NOE group on any of the demographic or birth variables examined, with the exception of length of stay in the hospital. See Table 3 for descriptive information. The OE and NOWS groups did not differ from the NOE group in sex, race, insurance type (all Fisher exact $P \mathrm{~s}>$ .60). Compared to the infants with NOE, the infants with OE (all $t \mathrm{~s}(1,26)>0.19$; all $P \mathrm{~s}>.19$ ) and infants with NOWS (all $t \mathrm{~s}(1,22)>0.20$; all $\left.P_{\mathrm{S}}>.05\right)$ did not differ in gestation (wks), birth weight (g), birth length (in), Apgar scores at 1 and 5 minutes. The infants with NOWS, however, had significantly longer hospital stays, than the infants with $\operatorname{NOE}(t(1,22)=$ 5.86; $P<.0001)$. The infants with $\mathrm{OE}$ showed a similar trend, but the difference in length of stay did not quite reach significance $(t(1,26)=2.03 ; P=.053)$.

\section{Maternal Demographics and Health}

The mothers of infants with OE and those with NOWS did not differ significantly from the mothers of infants in the NOE group on any of the demographic or birth variables examined, with the exception of maternal weight at delivery and mental health disorders. See Table 3 for descriptive information. Compared to the mothers of the NOE group, those of the OE group (all $t \mathrm{~s}(1,26)>0.19$; all $P \mathrm{~s}>.60)$ and NOWS group $($ all $t \mathrm{~s}(1,22)$ $>1.0$; all $P \mathrm{~s}>.16$ ) did not differ in age at delivery or parity (ie, number of births of greater than 24 weeks gestational age). While greater proportions of the mothers of infants with $\mathrm{OE}$ or 


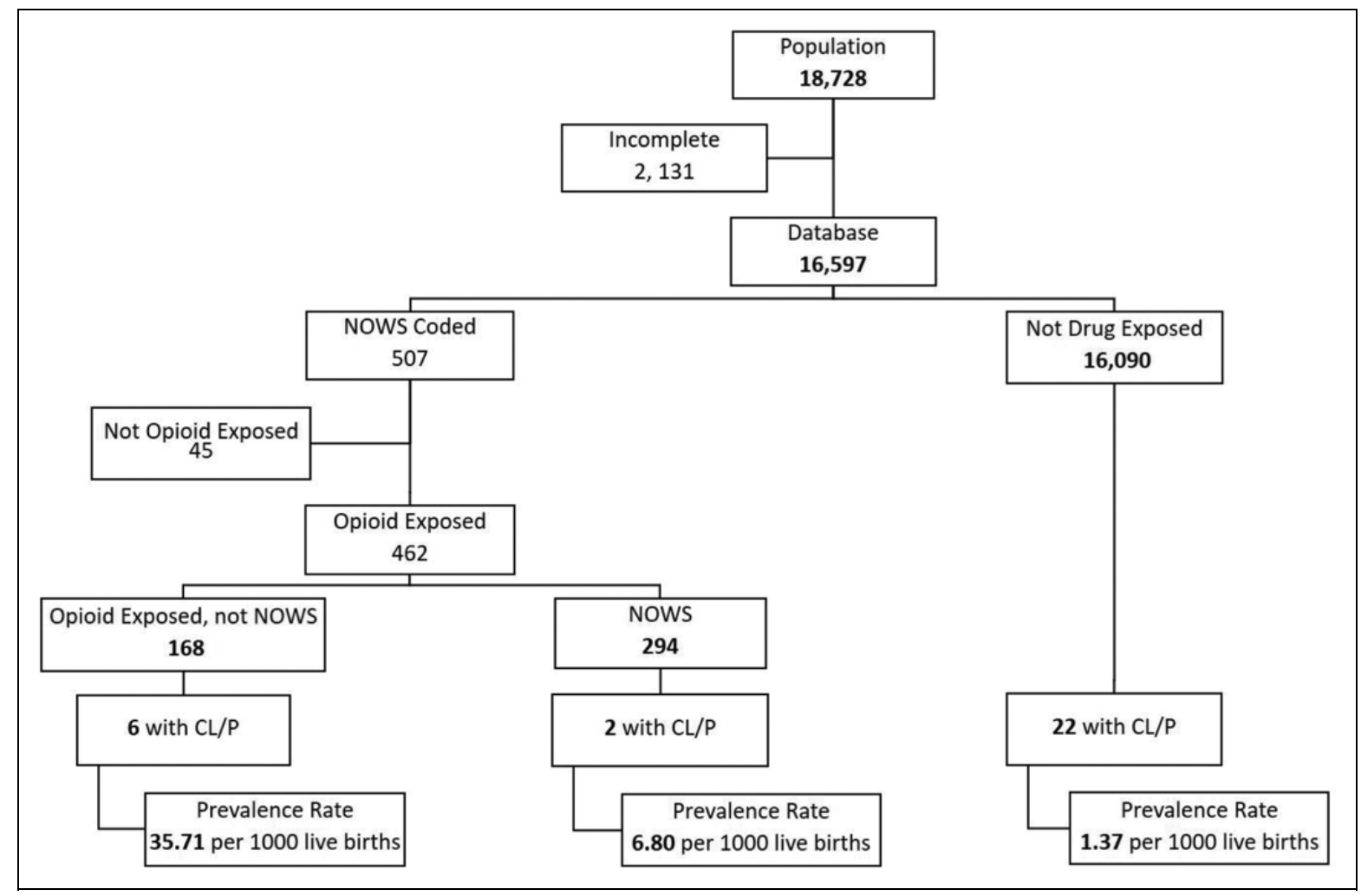

Figure I. Population and sample sizes, and prevalence rates of CL/P.

Table 3. Occurrence of Demographic and Contributing Factors in NOE, OE, and NOWS Groups With CL/P.

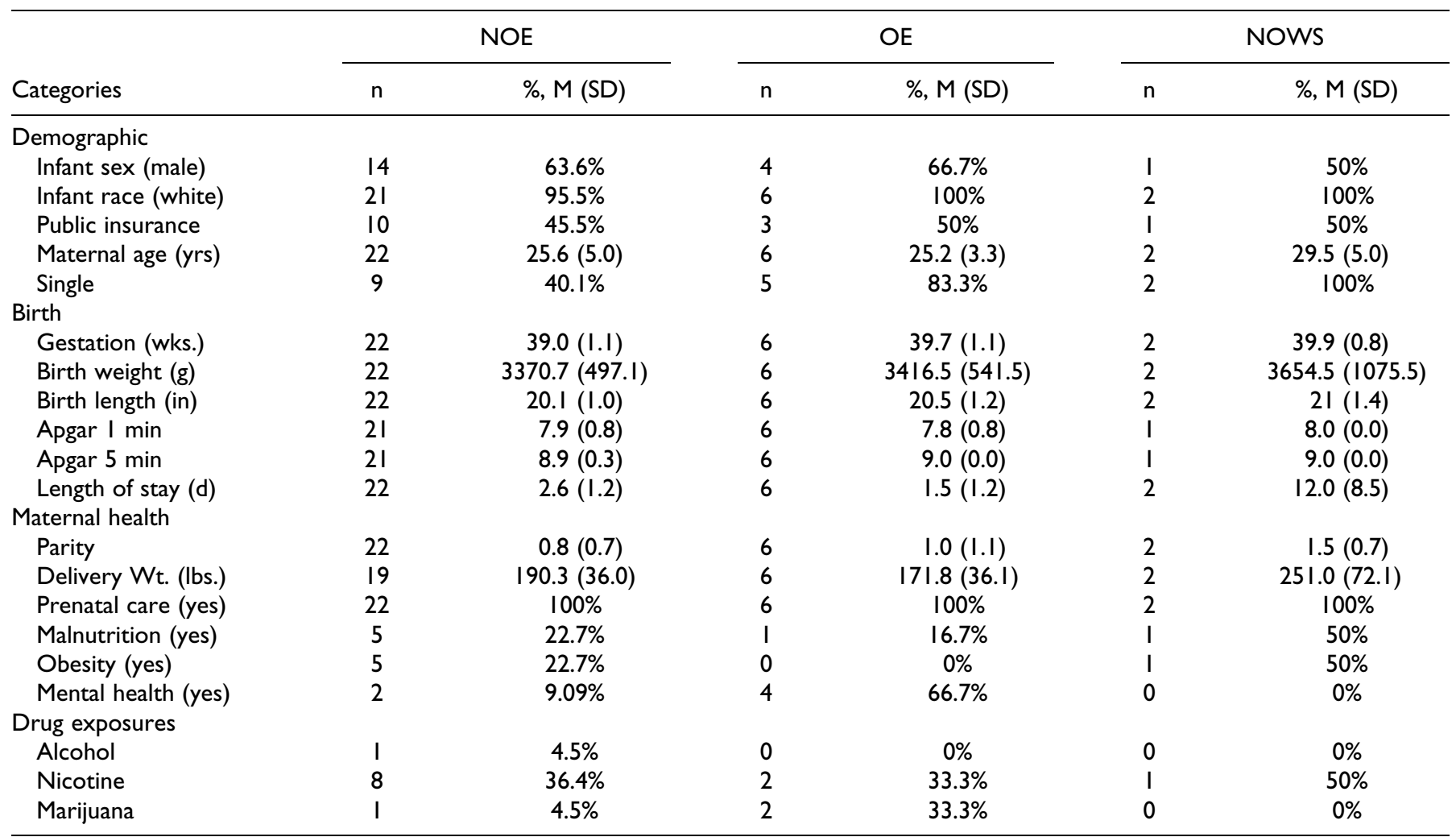

Abbreviations: d, days; g, grams; in, inches; lbs, pounds; M, mean; min, minutes; $n$, sample size; NOE, no opioid exposure; NOWS, neonatal opioid withdrawal syndrome; OE, opioid exposure; SD, standard deviation; wks., weeks. 
NOWS were single compared to mothers of infants with NOE, the differences were not significant (all Fisher exact $P \mathrm{~s}>.07$ ).

The mothers of infants with NOWS weighed significantly more than those of infants with $\operatorname{NOE}(t(1,22)=2.11$; $P=.048)$. The weights of the mothers of the OE group did not significantly differ from those of the NOE group $(t(1,26)=$ $1.10 ; P=.28)$. A significantly greater proportion of mothers of infants with $\mathrm{OE}$ experienced mental health disorders than those of infants with NOE $(P=.01)$. The proportions in the NOWS and $\mathrm{OE}$ groups did not differ $(P=.84)$. The proportion of mothers in the OE and NOWS groups did not differ significantly in malnutrition or obesity (all Fisher exact $P \mathrm{~s}>.25$ ) when compared to the mothers of the NOE group.

\section{Exposure to Other Substances}

There were no positive urine drug screen results or maternal self-report of benzodiazepines, cocaine, barbiturates, amphetamines, and codeine. The proportions of mothers of infants with OE or NOWS did not differ from those of infants with NOE in use of alcohol, nicotine, or marijuana (all Fisher exact $P_{\mathrm{S}}>$ $.10)$.

\section{Trimester of Opioid Use}

Of the 2 mothers of infants with NOWS, one reported she used opioids throughout the pregnancy, while the other reported she used only during the third trimester. Of the 6 mothers of infants with $\mathrm{OE}, 4$ reported opioid use during the first trimester at least. More specifically, 2 mothers reported opioid use throughout the pregnancy, 1 reported use only during the first trimester, 1 reported use only during the first and second trimesters, and 2 reported use only during the third trimester.

\section{Discussion}

\section{Prevalence of CL/P}

The prevalence of CL/P in this study's comparison sample was generally representative of those reported more broadly and in Mullens et al. (2019) and Danis et al. (2020). The prevalence per 1000 live births of CL/P in the NOE comparison group at 1.37 was almost identical to that of Danis et al. (2020) at 1.35. It was somewhat higher than the US national figure of 1.06 (National Institute on Dental and Craniofacial Research, nd) and the rates in Tennessee and Virginia at 1.10 and 1.05, respectively (National Birth Effects Prevention Network, 2010). This study's prevalence rate was lower than that reported by Mullens et al. (2019) at 1.63 and the international rate range at 1.42 to 2.00 (World Health Organization, 2001).

In the NOWS groups, the prevalence of CL/P per 1000 in this study at 6.80 was virtually identical to that of Mullins et al. (2019) at 6.79. Both of these prevalence numbers were much higher than that reported by Danis et al. (2020) at 3.13, most likely due to the national nature of their study and large population.
The similarities of our data for infants in the NOE and NOWS groups to that of other reports and studies gives initial credence to the surprisingly high prevalence of $\mathrm{CL} / \mathrm{P}$ in the newly introduced sample of infants with OE. They showed a prevalence rate of 35.71 per 1000 live births. However, this remarkable result needs verification through replication.

\section{Odds Ratios of CL/P}

Infants with NOWS. In comparison the infants with NOE, those with NOWS had a significantly higher odds for $\mathrm{CL} / \mathrm{P}$ and $\mathrm{CP}$ (5.00 and 10.98, respectively) but did not differ in their likelihood of CL and CLP. These findings of significance mirror those of Danis et al. (2020) though they report lower odds for $\mathrm{CL} / \mathrm{P}$ and CP (2.33 and 4.97, respectively). Mullens et al. (2019) also found significantly higher odds ratios for CL/P (4.18), but not for CP or CLP. However, they uniquely found an increased likelihood of CL, with an odds ratio of 5.92.

The differences in the odds ratios and patterns of significant differences for infants with NOWS may be related to a number of factors. Danis et al. (2020) ascribed the differences to sample demographics (ie, race and sex), sample size, and incidence of NOWS in different states across the US. This view is supported by WHO (2001), which attributes the range of prevalence to the considerable variance across geographical regions and ethnic groupings.

Another source of difference may be attributed to the use of different criteria across hospital systems in identification of NOWS. There is no commonly accepted protocol or standard endorsed by the American Medical Association for nonpharmacological or pharmacological intervention and monitoring of symptoms to aid diagnosis of NOWS (Kocherlakota, 2014). Also, this study made significant efforts to accurately identify infants with NOWS who received pharmacological intervention and those prenatally opioid exposed who did not receive pharmacological intervention and may or may not have had NOWS. This resulted in 45 infants initially coded as having NOWS being excluded. Furthermore, we divided the original NOWS sample into 2 distinct groups, NOWS and OE, based on a deep review of the infants' medical records. Thus, the infants with NOWS in our study may not have included some of the infants identified as NOWS in the studies of Mullens et al. (2019) and Danis et al. (2020). Furthermore, it may be that some of the infants identified as OE in our study appeared in their studies as NOWS. This may have contributed to differences in odds ratios across studies. Irrespective of classification, all 3 studies confirmed an association between NOWS and $\mathrm{CL} / \mathrm{P}$.

Infants with $O E$. The inclusion of infants with $\mathrm{OE}$ in this study provides new data about the likely teratogenicity of opioids for $\mathrm{CL} / \mathrm{P}$. This group showed significantly higher and concerning odds ratios for CL/P (27.05), CL (41.81), CP (19.26), and CLP (19.37) in comparison to infants with NOE. It appears that the current study corroborates previous studies (eg, Saxén, 1975a; Saxén, 1975b; Bracken and Holfrod, 1981; Thomas, 1995; 
Meyer et al., 2015) that pointed to the association of fetal OE and $\mathrm{CL} / \mathrm{P}$. Our data further specifies that in utero exposure to opioids is a contributory environmental risk factor in $\mathrm{CL} / \mathrm{P}$ whether or not the infants show withdrawal signs or require pharmacological intervention.

\section{Other Potentially Confounding Variables}

There were few differences in the demographic, maternal health, birth, or drug exposures variables that we explored. Among the few differences, the significantly longer length of stay in the hospital for infants with NOWS than those with NOE reflects the complexity of their care and recovery from withdrawal symptoms (Kocherlakota, 2014; Patrick et al., 2015). The mothers of infants with NOWS weighed significantly more and a significantly greater proportion of mothers of infants with $\mathrm{OE}$ experienced mental health disorders than those of infants with NOE.

The demographic and health conditions of mothers and infants in this study reflect the health disparities endemic in this rural Appalachia region (Erwin et al., 2017). Thus, with respect to confounding variables, the mothers and infants in the NOE group may not be as different from those in the OE and NOWS groups as they might be in other areas of the nation. The presentation of confounding variables in the NOE, OE, and NOWS groups did not differ. Thus, the potential unique contribution of prenatal exposure to opioids as the primary environmental difference between the groups is revealed.

\section{Limitations}

Like Mullens et al. (2019), our sample was limited to a specific geographical region in Appalachia, in contrast to the national database utilized by Danis et al. (2020). Also, given the relatively small numbers of infants in the NOE, OE, and NOWS groups, the current study lacked the power for confidently detecting differences in demographic and contributing factors between the NOWS group and the NOE and OE groups. Furthermore, the retrospective nature of the data prevented capture of a full spectrum of other potential confounding variables necessary for investigation of the multifactorial nature of $\mathrm{CL} / \mathrm{P}$.

\section{Future Directions}

Now that there are similar findings from 3 large scale studies of the association between prenatal $\mathrm{OE}$ and $\mathrm{CL} / \mathrm{P}$, consideration of a theoretical view is warranted. Both Mullens et al. (2019) and Danis et al. (2020) emphasized the need for better understanding of the environmental risk factors for $\mathrm{CL} / \mathrm{P}$ in the NOWS population. However, the likelihood of isolating risk factors individually is challenging, given the complexity of the population (Kocherlakota, 2014; Bailey et al., 2017). In the future, researchers may want to consider approaching this problem holistically. The Multifactorial Threshold (MF/T) model as applied to $\mathrm{CL} / \mathrm{P}$ offers this opportunity (Zajac and Vallino,
2017). The MF/T model postulates that when an individual has a predisposition toward a given disorder, and is exposed to certain environmental conditions, the disorder will present itself (Zajac and Vallino, 2017). For example, prenatal exposure to opioids along with other adverse environmental factors, combined with a genetic susceptibility of the fetus, may push the fetus over the threshold and lead to a CL/P.

\section{Conclusions}

This study clearly indicated that for infants prenatally exposed to opioids there is increased prevalence and likelihood of having $\mathrm{CL} / \mathrm{P}$. Together with the findings of the recent large-scale studies of Mullens et al. (2019) and Danis et al. (2020), it is clear that opioids are a substantial environmental risk factor for $\mathrm{CL} / \mathrm{P}$, particularly considering the opioid crisis in the US.

\section{Acknowledgments}

The authors would like to thank the members of the interprofessional NAS Working Group who shared their scholarly insights and literature about NOWS and its neurodevelopmental outcomes. We gratefully acknowledge Dr Beth Bailey for her help identifying infants with $\mathrm{CL} / \mathrm{P}$ within the database and the M.S. SLP students who contributed to the initial phase of this study.

\section{Declaration of Conflicting Interests}

The author(s) declared no potential conflicts of interest with respect to the research, authorship, and/or publication of this article.

\section{Funding}

The author(s) disclosed receipt of the following financial support for the research, authorship, and/or publication of this article: The creation of the database was financially supported in part by the Junior League of Johnson City, TN, USA.

\section{ORCID iD}

Kerry Proctor-Williams (D) https://orcid.org/0000-0003-0841-6468

\section{References}

Bailey BA, Wood D, Clements AD, Proctor-Williams K, Boynewicz K, Trivette C, Justice N. Polydrug use and other risk factors among women receiving MAT during pregnancy: challenges for research on health and developmental effects in infancy and beyond. Poster presented at: The Teratology Society 57th Annual Meeting; 2017; Denver, CO.

Barfield W. The Problem of Neonatal Abstinence Syndrome. Centers for Disease Control and Prevention. 2016. Accessed March 15, 2019. https://www.cdc.gov/cdcgrandrounds/pdf/archives/2016/ august2016.pdf

Bateman BT, Hernandez-Diaz S, Rathmell JP, Seeger JD, Doherty M, Fischer MA, Huybrechts KF. Patterns of opioid utilization in pregnancy in a large cohort of commercial insurance beneficiaries in the United States. J Am Soc Anesthesiol. 2014;120(5):1216-1224. doi:10.1097/ALN.0000000000000172

Benninger KL, Borghese T, Kovalcik JB, Moore-Clingenpeel M, Isler C, Bonachea EM, Maitre NL. Prenatal exposures are associated 
with worse neurodevelopmental outcomes in infants with neonatal opioid withdrawal syndrome. Front Pediatr. 2020;8(8):462zx.

Birth Defects State Profile-Tennessee. National birth defects prevention network. January 2010. Accessed October 18, 2019. https:// www.nbdpn.org/docs/TN_2010_C.pdf

Bowman CH, Horstman E, Nava-Sifuentes M, Sanders K, Townsend $\mathrm{S}$, Carder N, Proctor-Williams K. Infants with neonatal abstinence syndrome: who receives SLP services in the NICU? Poster presented at: the American Speech-Language-Hearing Association Convention; November 15, 2018; Boston, MA.

Bracken MB, Holford TL. Exposure to prescribed drugs in pregnancy and association with congenital malformations. Obstetr Gynecol. 1981;58(3):336-344.

Broussard CS, Rasmussen SA, Reefhuis J, Friedman JM, Jann MW, Riehle-Colarusso T, Honein MA. Maternal treatment with opioid analgesics and risk for birth defects. Am J Obstetr Gynecol. 2011; 204(4):314, e1-11.

Centers for Disease Control and Prevention. Prescription painkiller overdoses: a growing epidemic, especially among women. 2013. Accessed October 18, 2019. https://www.cdc.gov/vitalsigns/pre scriptionpainkilleroverdoses/index.html

Danis DO, Bachrach K, Piraquive J, Marston AP, Levi JR. Cleft lip and palate in newborns diagnosed with neonatal abstinence syndrome. Otolaryngol Head Neck Surg. 2020;163(1):1-7. doi:10. 1177/0194599820944899

Davies H, Gilbert R, Johnson K, Petersen I, Nazareth I, O’Donnell M, Guttmann A, Gonzalez-Izquierdo A. Neonatal drug withdrawal syndrome: cross-country comparison using hospital administrative data in England, the USA, Western Australia and Ontario, Canada. Arch Dis Child Fetal Neonatal Ed. 2016;101(1):26-30. doi:10. 1136/archdischild-2015-308948

Desai RJ, Hernandez-Diaz S, Bateman BT, Huybrechts KF. Increase in prescription opioid use during pregnancy among Medicaidenrolled women. Obstetri Gynecol. 2014;123(5):997-1002. doi: 10.1097/aog.0000000000000208

Erwin PC, Lindley L, Meschke LL, Ehrlich SF. Neonatal abstinence syndrome in East Tennessee: characteristics and risk factors among mothers and infants in one area of Appalachia. $J$ Health Care Poor Underserved. 2017;28(4):1393.

Fill MMA, Miller AM, Wilkinson RH, Warren MD, Dunn JR, Schaffner W, Jones TF. Educational disabilities among children born with neonatal abstinence syndrome. Pediatrics. 2018;142(3):e20180562.

Finnegan LP, Connaughthon JF, Kron RE, Emich JP. Neonatal abstinence syndrome: assessment and management. Addict Dis. 1975; 2(1-2);141-158.

Han B, Compton WM, Blanco C, Crane E, Lee J, Jones CM. Prescription opioid use, misuse, and use disorders in U.S adults: 2015 national survey on drug use and health. Ann Intern Med. 2017; 167(5):293-301. doi:10.7326/m17-0865

Hays WL. Statistics. 5th ed. Harcourt Brace College Publishers; 1994. Jansson LM, Velez M, Harrow C. The opioid exposed newborn: assessment and pharmacologic management. J Opioid Manage. 2009;5(1):47-55.

Jones HE, O'Grady KE, Johnson RE, Velez M, Jansson LM. Infant neurobehavior following prenatal exposure to methadone or buprenorphine: results from the neonatal intensive care unit network neurobehavioral scale. Subst Use Misuse. 2010;45(13): 2244-2257. doi:10.3109/10826084.2010.484474

Kim HY.Statistical notes for clinical researchers: Chi-squared test and Fisher's exact test. Restor Dent Endod. 2017;42(2):152. doi:10. 5395/rde.2017.42.2.152

Ko JY, Patrick SW, Tong VT, Patel R, Lind JN, Barfield WD. Incidence of neonatal abstinence syndrome-28 states, 1999-2013. MMWR Morb Mortal Wkly Rep. 2016;65(31):799-802. doi:10. 15585/mmwr.mm6531a2

Kocherlakota P. Neonatal abstinence syndrome. Pediatrics. 2014; 134(2):e547-e561. doi:10.1542/peds.2013-3524

Kolodny A, Courtwright DT, Hwang CS, Kreiner P, Eadie JL, Clark TW, Alexander GC. The prescription opioid and heroin crisis: a public health approach to an epidemic of addiction. Ann Rev Public Health. 2015;36(1):559-574. doi:10.1146/annurev-publhealth031914-122957

Lind JN, Interrante JD, Ailes EC, Gilboa SM, Khan S, Frey MT, Dawson AP, Honein MA, Dowling NF, Razzaghi H, et al. Maternal use of opioids during pregnancy and congenital malformations: a systematic review. Pediatrics. 2017;139(6):1-25. doi:10.1542/ peds.2016-4131

McQueen K, Murphy-Oikonen J. Neonatal abstinence syndrome. New Engl J Med. 2016;375(25):2468-2479. doi:10.1056/nejmra1600879

MEDCALC. MedCalc for Windows (version 19.4). MecCalc Software. 2020. Accessed October 13, 2020. https://www.medcalc.org/calc/ odds_ratio.php

Meyer MC, Johnston A, Crocker A, Heil S. Methadone and buprenorphine for opioid dependence during pregnancy. $J$ Addict Med. 2015;9(2):81-86. doi:10.1097/ADM.0000000000000092

Mullens CL, McCulloch IL, Hardy KM, Matthews RE, Mason AC. Associations between orofacial clefting and neonatal abstienece syndrome. Plast Reconstr Surgery Glob Open. 2019;7(1):e2095. doi:10.1097/GOX.0000000000002095

National Institute on Dental and Craniofacial Research. Prevalence of cleft lip and palate. Accessed November 19, 2020. https://www. nidcr.nih.gov/research/data-statistics/craniofacial-birth-defects/ prevalence

National Institute on Drug Abuse. Dramatic increases in maternal opioid use and neonatal abstinence syndrome. 2019. Accessed November 19, 2020. https:/www.drugabuse.gov/drug-topics/ trends-statistics/infographics/dramatic-increases-in-maternalopioid-use-neonatal-abstinence-syndrome

National Institute on Drug Abuse. Monitoring the future 2019 survey results: overall findings. 2016. Accessed November 19, 2020. https://www.drugabuse.gov/related-topics/trends-statistics/moni toring-future

Oei JL, Melhuish E, Uebel H, Azzam N, Breen C, Burns L, Hilder L, Bajuk B, Abdel-Latif ME, Ward M, et al. Neonatal abstinence syndrome and high school performance. Pediatrics. 2017;139(2):1-10.

Patrick SW, Barfield WD, Poindexter BB. Neonatal opioid withdrawal syndrome. Pediatrics. 2020;146(5):e2020029074. doi:10.1542/ peds.2020-029074

Patrick SW, Davis MM, Lehmann CU, Cooper WO. Increasing incidence and geographic distribution of neonatal abstinence syndrome: United States 2009 to 2012. J Perinatol. 2015;35(8): 650-655. doi:10.1038/jp.2015.63 
Raval A, Pan X, Sambamoorthi U. FDA CDX category medication use during pregnancy in the United States. Value Health. 2014; 17(7):A519. doi:10.1016/j.jval.2014.08.1618

Saxén I. The association between maternal influenza, drug consumption and oral clefts. Acta Odontologica Scandinavica. 1975a;33(5): 259-267. doi:10.3109/00016357509004631

Saxén I. Associations between oral clefts and drugs taken during pregnancy. Int J Epidemiol. 1975b;4(1):37-44. doi:10.1093/ije/4. 1.37

StatSoft Inc. STATISTICA Data Analysis Software System (version 9.0). 2009. www.statsoft.com

Thomas DB. Cleft palate: mortality and morbidity in infants of substance abusing mothers. J Pediatr Child Health. 1995;31(5):457-460.

World Health Organization. (2001) Global Registry and Database on Craniofacial Anomalies: Report of a WHO Registry Meeting on
Craniofacial Anomalies. Bauru, Brazil: World Health Organization.

Wu LT, Zhu H, Swartz MS. Treatment utilization among persons with opioid use disorder in the United States. Drug Alcohol Depend. 2016;169:117-127.

Yang T, Walker MC, Krewski D, Yang Q, Nimrod C, Garner P, Fraser W, Olatunbosun O, Wen SW. Maternal characteristics associated with pregnancy exposure to FDA category C, D, and X drugs in a Canadian population. Pharmacoepidemiol Drug Saf. 2008;17(3): 270-277. doi:10.1002/pds. 1538

Yazdy MM, Desai RJ, Brogly SB. Prescription opioids in pregnancy and birth outcomes: a review of the literature. J Pediatr Genet. 2015;4(2):56-70.

Zajac D, Vallino L. Evaluation and management of cleft palate. Developmental Perspective. Plural Publishing; 2017. 